\title{
MUNDO: O WALTEN SOBERANO DE MARTIN HEIDEGGER E SEU ADVOGADO JACQUES DERRIDA
}

\author{
WORLD: MARTIN HEIDEGGER'S SOVREREIGN WALTEN \\ AND HIS LAWAYER JACQUES DERRIDA
}

\section{Gabriel Rezende de Souza Pinto*}

\begin{abstract}
RESUMO: Soberania e a questão do mundo. Seguindo a proposta de Jacques Derrida de ler de perto a vinda, a chegada da Soberania por meio do conceito de mundo em $O$ s conceitos fundamentais da metafisica: mundo, finitude e solidão, de Martin Heidegger, este artigo expande seu escopo para alcançar anteriores significados de mundo em sua obra. Este movimento permite uma compreensão muito mais ampla dos caminhos que conduzem Heidegger ao ponto em que a soberania se transforma em questão. Após esta recapitulação, guiada sobretudo pela Fenomenologia da vida religiosa e por Sobre a Essência do fundamento, são tratados os temas envolvidos na análise comparativa feita por Heidegger, a qual impede que o animal tenha acesso à diferença ontológica e, por essa mesma razão, coloca o ser humano, o Dasein, numa posição única de superioridade e solidão. Enquanto Heidegger está interessado em traçar uma linha que distingue os homens de todos os demais entes, Derrida ressalta como o verbo alemão walten é empregado com o objetivo de estabelecer aquela diferença com apoio em algo maior que qualquer espécie de poder onto-teo-lógico ou antropológico conhecido pela tradição filosófica. $\mathrm{O}$ walten apela para algo completamente outro: soberania para além de toda soberania, ultra-soberania.
\end{abstract}

PALAVRAS-CHAVES: Mundo. Soberania. Martin Heidegger.

ABSTRACT: Sovereignty and the question of the world. Following Jacques Derrida's proposal to read closely the coming, the arrival of Sovereignty through the concept of world in Martin Heidegger's The fundamental concepts of Metaphysics: world, finitude, solitude, this paper expands on that point to survey as well earlier signifieds attached to this very same signifier in his works. This movement allows a much broader comprehension of the paths that conducted Heiddeger to the point where Sovereignty was at stake. After that recapitulation, guided above all by the Phenomenology of the religious life and On the essence of ground, this paper addressed the issues involved in Heidegger's comparative analyses that precludes the animal from accessing the ontological difference and thus exalting the human being, the Dasein as something unique in its position of solitude. Whereas Heidegger is interested in drawing a line that distinguishes men from every other being, Derrida points out how the German verb walten is employed to establish that ontological difference with reference to something that is greater than all the forms of onto-teo-logical or anthropological power known in philosophical tradition. The walten claims something entirely other: sovereignty beyond any sovereignty, an ultra-sovereignty.

KEYWORDS: World. Sovereignty. Martin Heidegger.

* Mestrando em Direito pela Universidade de Brasília (UnB). Membro do Grupo de Estudos pela Internacionalização do Direito (IDEJUST-USP) e do Grupo de Pesquisa Percursos, Narrativa e Fragmentos: História do Constitucionalismo Brasileiro. Bolsista da CAPES. E-mail: grezende@gmail.com 


\section{INTRODUÇत̃̃O}

Trata-se da questão do mundo. Da questão sobre o mundo. Obviamente, não uma questão qualquer: ao menos não uma que se preocupe em responder tout court à pergunta sobre a essência do mundo. A esta só se pode responder com o silêncio. Talvez. Talvez, num sentido próximo àquele de Wittgenstein: "Sobre aquilo que não se pode falar, deve-se silenciar" (1993, p.111). O mundo como algo diante do que só se pode calar.

Assim como o silêncio de Wittgenstein pôde ocorrer somente ao final de seu Tractatus, o silêncio do qual tratará este artigo necessita também de um longo caminho. Um caminho não apenas de construção, mas de refinamento da questão. É necessário pensar o discurso que produz o mundo como o indizível do qual decorrem todos os enunciados possíveis - toda enunciabilidade.

Mundo também é um vocábulo técnico. Apesar da precariedade deste último termo - sobretudo diante da matriz filosófica que se abordará em instantes -, seu uso deixa ver que ele ocorre de modo específico no interior de uma certa filosofia. Caso se prefira, no interior de uma certa família - afinal, não era este o objetivo de Husserl? Daí porque no caminho aqui proposto - que não pode deixar de ser aquele de um trabalho do conceito sem conceito - pretenda-se interrogar não somente a essência de um fenômeno, mas a recorrência de um filosofar.

\section{O mundo.}

Mas não o mundo por si ou em si, mas o mundo numa direção muito específica. Este artigo se insere no contexto mais amplo de investigação sobre a soberania ou, caso se prefira, da soberania como questão, uma Souveränitätsfrage posicionada a meio caminho entre o Direito Constitucional e o Direito Internacional com o objetivo claro de se pensar sua relação com os direitos fundamentais. Este acoplamento não é novo: reside na raiz daquilo que pode ser entendido como constitucionalismo - próprio ao debate que cindiu liberais e republicanos ${ }^{1}$ - compondo os polos antagônicos ${ }^{2}$ que possibilitaram a compreensão das noções de política e direito nas democracias do ocidente. Do mesmo modo, a grande odisseia do direito internacional no século XX é sobredeterminada pela tensão entre as exigências normativas do universalismo (em especial a ascensão dos direitos humanos como fator de composição da racionalidade do direito) e a facticidade de um relativismo de poderes dispersos em soberanias nacionais ${ }^{3}$. $\mathrm{O}$ desenvolvimento deste modelo, a um só tempo explicativo e regulatório, conduziu a uma situação-limite (Grenzsituation) de altíssima complexidade: a soberania impossível de uma volonté générale sobreposta aos direitos fundamentais no plano interno se assoma à soberania

\footnotetext{
1 Sobre o tema, ver HABERMAS (1996, p. 84 et seq.).

2 Sobre o paradoxo necessário de direitos fundamentais e soberania popular, ver ELSTER, Jon (2000).

3 DELMAS-MARTY, Mireille. Les forces imaginantes du droit (i): le relatif et l'universel. Paris. Seuil, 2004.
} 
canalha (rogue) dos Estados que se eximem da construção de um direito internacional cosmpolita para além do internacionalismo. Pensar o direito em nossas sociedades contemporâneas significa, necessariamente, tematizar profundamente o lugar e o significado da soberania em qualquer das formas que possa assumir ${ }^{4}$.

Pretende-se, portanto, desenvolver a soberania como questão, denotando evidentemente que se parte de uma compreensão prévia de que, no estado atual de Filosofia e Teoria do Direito a mesma se encontra sub-desenvolvida, sub-trabalhada, sub-problematizada. Se não se deve temer os monstros jurídicos, como sugere Mireille Delmas-Marty em seu Les forces imaginantes du Droit (III) - La refondation des pouvoirs ${ }^{5}$, talvez não se deva tampouco ter medo de trilhar as trilhas mais inusitadas. É precisamente nesse sentido que se aceita aqui o desafio posto por Jacques Derrida no Séminaire La Bête et et le Souverain, volume II: como pensar a soberania e a animalidade, a besta e o soberano a partir de um lugar em que poucos poderiam supor encontrar algo que se relacionasse minimamente com Direito e Política: Martin Heidegger. Como pensar a soberania a partir de Heidegger - eis a questão deste artigo.

Jacques Derrida, ao longo de seu derradeiro seminário, afirmou que estudaria de perto a ocorrência da soberania a partir da noção de mundo tal como fora articulada em Os conceitos fundamentais da metafísica: mundo, finitude, solidão, texto que corresponde ao seminário ofertado por Heidegger entre os anos de 1929 e 1930. Seu contexto histórico por si só já poderia ser alvo de um sem-número de especulações. Basta pensar na completa crise política da República de Weimar - e da própria Constituição, como chamam a atenção Arthur Jacobson e Bernhard Schlink (2000) -, aprofundada pela devastadora crise econômica de 1929. Alguns dos mais importantes escritos produzidos no séc. XX sobre soberania datam dos anos imediatamente anteriores ao seminário. Pense-se, por exemplo, na Teologia Política, de 1922, e na Teoria da Constituição, de 1927, ambos livros de autoria de Carl Schmitt (2004; 1996); ou, também do ano de 27, o famoso ensaio A soberania, de H. Heller. Seria bastante relevante um estudo que se colocasse a tarefa de compreender as contaminações recíprocas destes textos todos; e, para além, da própria temática da soberania com as exigências sociais e os debates políticos que se multiplicavam no período. Essa via, entretanto, não será diretamente aqui explorada. Antes, com o objetivo específico de desenvolver ferramentas conceituais inovadoras para se atacar a questão da soberania, parece promissora a idéia de compreender a forma com que walten - verbo intraduzível sobre o qual se falara mais -, homem e animal estão umbilicalmente conectados com o mundo. Que mundo é este que eles co-habitam? Qual mundo comum os traz à luz? Como é possível aí a questão da soberania?

${ }_{4}$ Ver, nesse sentido, MARRAMAO (2000).

5 DELMAS-MARTY, Mireille. Les forces imaginantes du droit (iii): la refondations des pouvoirs. Paris: Seuil, 2007, p. 99 et seq. 
O que é o mundo?

Ausente a possibilidade de uma metodologia anterior (HEIDEGGER, 1976, p. 5 et seq) que assegure qualquer racionalidade; ausente toda metalinguagem possível; a escolha do caminho se dará sempre por um golpe de força ou por uma peripécia. Uma nota de arbitrariedade se fará sentir ao traçar a rota, ainda que se espere dissipála à medida que os argumentos avancem e os pressupostos sejam mais refinados e explicitados. De toda sorte, tem-se por finalidade um deslocamento e um aprofundamento do "convite" feito por Derrida: buscar compreender a soberania na questão do mundo. Antes, contudo, é preciso entender como a própria noção de mundo é trabalhada pelo próprio Heidegger em momentos distintos de sua obra. Como fora possível a questão do mundo? De que modo e sob quais condições Heidegger é levado a pensar mundo como questão (Weltfrage) em Os conceitos fundamentais da metafísicia? Este caminho tem uma história que não pode ser negligenciada caso se pretenda realizar um exercício hermenêutico digno deste nome.

Ao longo do texto, será ensaiado um exercício de explicitação dos usos do termo mundo até que se possa chegar à sua questão. E é justamente este o limite: um limiar, limen. A primeira parte do artigo se propõe a jogar luz sobre a ideia de mundo nos escritos iniciais de Heidegger. Ao contrário da via óbvia de conclusão desta tarefa, o texto privilegiado não será Ser e Tempo: afinal, sobre ele muito já foi dito e escrito. Ademais, aposta-se que num estado anterior, ainda menos refinado, as ideias estejam mais claras e algumas propostas possam ser melhor evidenciadas. $\mathrm{O}$ texto-guia a servir de astrolábio é, por essa razão, a Fenomenologia da Vida Religiosa.

Passa-se, em seguida, a uma abordagem diferente dada pelo próprio Heidegger. Em Sobre a essência do fundamento, o diálogo claro com Kant torna-se altamente produtivo. Ele permite, sobretudo, que uma nova coloração seja dada à noção de mundo, unindo-a a um novo conjunto de termos com que fará sistema posteriormente. Para além disso, esse é um texto no qual mais explicitamente do que antes o mundo é, enquanto tal, objeto de um excurso analítico: Heidegger se proporá ali a fazer uma história da palavra mundo em suas principais ocorrências.

Finalmente, a parte final é dedicada a $O$ s conceitos fundamentais da metafísica e ao surgimento da questão do mundo como uma questão de soberania - uma soberania arque-soberana do walten. Para tanto será estudada a apropriação bastante peculiar que Derrida faz desse texto na tentativa de tematizar a besta e o soberano. Para entender os riscos presentes aqui, será preciso mergulhar profundamente nos textos, nas nuances, nos léxicos, na língua de Heidegger; e segui-lo, tanto quanto possível nas trilhas que ele mesmo se proporá. Não por outra razão, dirá aos participantes de seu seminário que ele, Jacques Derrida, “se fará de advogado [de Heidegger] com toda a lealdade necessária" (DERRIDA, 2010, p. 142, tradução nossa) ${ }^{6}$.

\footnotetext{
6 No original: “(...) et m'en faire l'avocat avec toute la loyauté requise”.
} 
Derrida advogado de Heidegger. O mundo. A soberania.

$\mathrm{O}$ mundo, portanto.

\section{O MUNDO NOS PRIMEIROS ESCRITOS DE MARTIN HEIDEGGER}

A dificuldade de se separar em quadros estanques o pensamento de um autor tão complexo como Martin Heidegger é autoevidente. Sobretudo porque a forma de abordar aquilo que aqui está sendo chamado de primeiros escritos pode variar bastante, dando azo a interpretações muitas vezes discrepantes. Poder-se-ia tratar destes textos como se nada mais fossem do que a preparação para uma reflexão maior que ocorreria quando suas propostas estivessem mais amadurecidas; em Ser e Tempo, por exemplo. Outra abordagem, muito comum no mais das vezes, pretenderia lê-los como se escritos de juventude fossem, ou seja, como um conjunto de insights, ideias que não guardam nenhuma correspondência - a não ser aquelas meramente anedóticas - com os escritos da maturidade. Ambos os enfoques, todavia, carregam em si concepções prévias que nada mais fazem do que criar barreiras que impedem um diálogo prolífico entre os textos.

A expressão primeiros escritos, portanto, pretende simplesmente colocar em jogo um agrupamento cronológico. Outro nome poderia ser dado à reunião dos textos que servem de primeiro ancoradouro para que se interrogue em Heidegger a questão do mundo. Optou-se por este.

A seleção do texto condutor da investigação, tampouco, segue uma ordenação anterior totalmente estruturada. Diferentes escritos poderiam ser trazidos à tona e, igualmente neles, seriam encontradas as marcas desta primeira reflexão sobre o mundo. Aquele aqui debatido, entretanto, carrega certa claridade que facilita a argumentação proposta. Mais do que isso, torna evidente a proximidade entre mundo e a inovadora concepção de Filosofia que propõe Martin Heidegger.

Proximidade e distância, afinal.

Assunto de topografias.

É, sem dúvida, o aspecto topográfico que primeiro chama a atenção. O exemplo do seminário de inverno de 1920/21, publicado sob o título Fenomenologia da vida religiosa é bastante produtivo neste sentido. Torna-se uma constante em Heidegger a ocorrência da palavra (do significante) mundo logo nas primeiras linhas dos textos. Justamente ali na introdução, onde se trata de correlacionar o significado que a introdução adquire no interior do filosofar e, também, de encetar uma divisão mais profunda entre a Filosofia e as Ciências. Todas essas dimensões estão umbilicalmente ligadas em sua proposta, de modo que, em seu argumento, não é mais possível falar sobre a Filosofia, seu lugar, sua história, suas especificidades, sem traçar uma linha que a separe radicalmente de toda ciência, de toda cientificidade, de todos os predicados que o senso comum - e também o senso comum filosófico - costuma lhe atribuir. 
É neste locus que o mundo ocorre: neste espaço - e é de espaços que se trata, afinal - em que a Filosofia não é possível sem uma virada (Umwendung): "Na realidade, cada caminho, de alguma maneira, conduz apenas diante da filosofia, não porém até ela. A filosofia mesma só é alcançada por meio de uma inversão do caminho" (HEIDEGGER, 2010, p. 15). Que virada é esta? Que virada é possível, com efeito, que não seja mais uma simples inversão; como fora o neokantismo de Nartop e seu deslocamento da objetivação para a esfera do sujeito? De que giro estaria a falar Heidegger quando descreve sua própria Filosofia?

$\mathrm{Na}$ Fenomenologia da Vida Religiosa essa virada tem nome certo: a experiência fática da vida (Die faktische Lebensfahrung). É este sintagma o responsável por reunir o núcleo duro da tese segundo a qual seria infrutífera a busca por um objeto da Filosofia, uma vez que essa não se ocupa de objetos. Para além de toda objetualidade, de toda parcialidade com que a Ciência delimita seus campos, suas divisões; enfim, para além de todo o conhecimento, o filosofar, definido a partir da experiência fática da vida, orienta-se "pela colocação ativa e passiva do homem no mundo" (HEIDEGGER, 2010, p. 16, itálico nosso). Na versão para o português optou-se por traduzir Stellung como colocação. O collocāre traz em si a ideia de pôr algo em algum lugar, mas também a de reunir e fundamentar. Difícil imaginar alguma palavra que melhor sirva à proposta de Heidegger.

O homem colocado ativa e passivamente no mundo (Welt).

Ainda que a noção que começa a se delinear necessite de mais algum trabalho, de mais elaboração, sua versão preliminar já é suficientemente clara no que concerne à resposta dada por Heidegger ao dilema da caracterização da Filosofia. Ao se colocar o homem no mundo, o referente da experiência ${ }^{7}$ deixa de ser um objeto qualquer - ou mesmo todos os objetos - para se tornar o mundo ele próprio ${ }^{8}$. É este o passo responsável pelo sensível distanciamento que se anuncia em relação ao pensamento de Edmund Husserl. Ainda que, neste momento, Heidegger declare - repita-se, declare - estar desenvolvendo uma pesquisa de cunho tipicamente fenomenológico, é muito difícil sustentar coisa semelhante. Não se trata apenas de apontar pura e simplesmente as contradições que se evidenciam entre os dois autores, mas, sobretudo, de observar como Heidegger parece construir sua hipótese em resposta aos problemas - e soluções - que seu professor havia desenvolvido.

Basta ler as primeiras páginas das Meditações cartesianas (1982) para se compreender como a cisão sujeito-objeto, como problema de fundamentação da própria Filosofia e do

7 Na passagem do texto que ora se ensaia uma leitura, Heidegger utiliza a palavra "experimentar" (erfahren), mas utiliza o sinal diacrítico do travessão e, logo em seguida, insere a palavra "vivenciar" (erleben). Tal recurso estilístico deixa entrever os diálogos que ele pretende estabelecer. Aqui, claramente, com toda a tradição que remonta a Dilthey. Cf. DILTHEY (1985).

8 Para uma crítica dos excessos que conduziram a um rebaixamento da Erfahrung em prol da Erlebnis, ver MARRAMAO (1995) 
conhecimento em geral, e sua pretensa superação por meio das noções de intencionalidade e constituição, formam um conjunto definidor do estatuto do filosofar. Por outro lado, quando Heidegger passa a operar com a noção de mundo, quando torna expressa sua concepção de que a Filosofia tem que ver com a experiência fática da vida, anuncia-se uma outra maneira de ler o problema. Sua fundamentação - a fundamentação sobre si mesma, caso se prefira - da Filosofia, i.e., seu discurso sobre o próprio do filosofar parte do fracasso que identifica na Fenomenologia em sua tentativa de retornar às "coisas mesmas". Uma fenomenologia transcendental, entendida como modificação radical da tese da orientação natural (HUSSERL, 1983, p. 57 et seq) fracassa por não perceber que havia algo mais originário, algo anterior a qualquer possibilidade de conhecimento advindo de uma redução transcendental. Nas palavras de Ernildo Stein:

Heidegger [um] dia fizera-lhe [a Husserl] uma observação dizendo que a redução transcendental excluía algo que não podia ser excluído da Filosofia. Que na redução transcendental não se tematizava o eu-empírico que sustentava a redução transcendental (STEIN, 2004, p. 27)

A experiência fática da vida; a vivência do mundo é a tentativa de Heidegger de oferecer uma solução às aporias em que se encontrava estagnada a Fenomenologia ainda que alguém como Føllesdal recuse tamanha inovação (1993). Em o fazendo, o mundo pode ser visto como espacialização - mas uma espacialização dotada de um sentido muito específico. Não se trata de modo algum da colocação do homem num lugar qualquer, ou seja, num lugar físico $x$ ou $y$, num lugar concreto. Se a palavra espaço pode aqui ser utilizada, é somente para descrever uma certa ideia de extensão; a extensão do conjunto de nexos, conexões vivenciais da própria estrutura ontológica. O mundo é uma espécie de contexto originário; de horizonte de relações. Na lição de Dreyfus:

Para desenvolver uma verdadeira ontologia, Heidegger utiliza seu próprio termo, isto é, Verhalten, que traduzo aqui por comportamento, a fim de definir a maneira com que o ser humano se relaciona com as coisas (DREYFUS, 1993, p. 292, tradução nossa) ${ }^{9}$.

Daí porque o que importa e, a fortiori, o que é próprio ao filosofar não é a descrição de quididades, nem sequer a interpelação de essências. O mundo possui como conteúdo um como (Wie) e não um quê (Was), no sentido de que a Filosofia se ocupa dos modos como se dão as vivências: modos esses a serem preenchidos, atualizados em cada realização concreta. Na leitura sintética de Stein, “o mundo é o como do homem” (2004, p. 147).

Este como, nos escritos iniciais de Heidegger, dividia-se em três categorias. Mundo circundante (Umwelt), como aquilo que vem ao encontro do homem, podendo se tratar de objetos, coisas, ideias etc.; Mundo compartilhado (Mitwelt), como relação com os

9 No original: "Pour développer une véritable ontologie, Heidegger utilise son propre terme, soit Verhalten, que je traduis par « comportement » [comportment], afin de définir la manière dont l'être humain se rapporte aux choses". 
outros homens numa situação fática bem determinada; Mundo próprio (Selbstwelt), o mundo do eu-mesmo. Pelo evidente esquematismo e pelo fato de ter sido deixado de lado posteriormente, esse quadro de divisões analíticas interessa pouco. Todavia, se no lugar de tentar ler ali uma caracterização ampla e completa, for possível enxergar o encadeamento do argumento heideggeriano, o que ganha prevalência é uma certa insistência no Mundo circundante. A razão disso aponta para outra importante contribuição presente nos primeiros escritos: o significar.

A Fenomenologia da Vida Religiosa carrega uma reflexão sobre a significância (Bedeutsamkeit). A descrição da vivência numa experiência fática da vida é caracterizada pela significância: todo e qualquer conteúdo é - desde sempre, poderia um estar tentado a dizer - dotado de significado. 0 mundo, enquanto tal, experiência originária espacializada segundo a lógica de uma arqueconexão, é, por este exato traço distintivo, matriz dos significados. As coisas, antes mesmo de serem objetos, de serem alvos de um conhecimento objetivante, já possuem ali, naquela cadeia de relações da vida fática, um significado.

Possibilitar os significados é próprio do mundo.

Ernildo Stein resume bem essa condição:

Ora, essa perseguição era quase obsessiva naquela época. Era a busca de uma matriz a partir da qual originava-se toda a nossa capacidade de designar, de referir, reconhecer o que foi referido, enfim, de todos os processos ligados à ação de significar. A busca dessa matriz era o que se encontrava encoberto tanto na idéia de mundo vivido como na idéia de ser-no-mundo. (...) Essa questão do mundo vivido não é tanto o antepredicativo, o pré-lógico - o que algumas vezes foi chamado de logicamente nu - simplesmente, mas é muito mais a busca da chamada matriz da significabilidade. Se olharmos isso desse modo, então, as coisas ficam muito mais claras, mais compreensíveis para nós. Mas, fica difícil olhar desse modo, pois a matriz da significância está na existência concreta, no fato de sermos. Por isso, nenhum de nós se encontra desligado dessa matriz da significância. É por causa dessa matriz que cada um de nós é capaz de significar, de dar significados (STEIN, 2004, p. 33-35).

Para além de toda abordagem teórica, de todo conhecimento (científico): o modo de conhecer que ora se desenha é aquele da vivência do homem inserido no mundo, portanto, inserido no significado. Novamente, a cisão sujeito-objeto é superada porque o que se investiga é anterior a ela; possibilitando-a mesmo. Algo que fica bastante claro quando, ao abordar o si-mesmo, Heidegger está em condição de dizer que “(...) em momento algum experimento meu eu em separado, mas já sou e estou sempre preso a meu mundo circundante" (HEIDEGGER, 2010, p. 18). Mais adiante, ele dirá que "O fático que é assumido pelo conhecimento não possui objetos, mas apenas caráter de significância que livremente pode se transformar-se num conjunto de objetos conformados" (HEIDEGGER, 2010, p. 18). Resta claro que o mundo é um "lugar" anterior - no sentido de fundamental - às outras formas de apreensão de conhecimento e de objetivação.

Ali se radica a Filosofia. 
De fato, este excurso pela Fenomenologia da vida religiosa elucida bem o que é a proposta filosófica de Martin Heidegger e como sua noção de mundo - arqueconexão das conexões e matriz de significado - é a pedra angular daquilo que ele está chamando de uma "virada" na Filosofia.

Ainda que de modo mais refinado, sobretudo do ponto de vista do léxico, do vocabulário empregado e da sistematicidade das proposições, Ser e Tempo parece ser muito mais o ponto de cumeada de todas essas ideias. Uma rápida passagem pelo parágrafo 18 de Ser e Tempo pode ser bastante produtivo.

A divisão esquemática de Umwelt, Mitwelt e Selbstwelt não mais é empregada como tal. Todo peso recai agora sobre a categoria de ser-no-mundo (In-der-Welt-sein) que, em verdade, é um outro nome a ser dado ao Dasein. A preposição em combinada com o artigo definido continua a evidenciar a colocação do homem no mundo, exatamente no sentido (muito específico) de espacialização que vem sendo aqui tratado. Uma arqueligação do homem (agora sempre chamado de Dasein) com o mundo que não se estabelece a partir de nenhuma consciência teórica, mas antes é o resultado de um copertencimento. Em suma, o Dasein é desde sempre mundo, no mundo; inserido naquele conjunto de relações que é matriz de significabilidade.

Nós damos o nome de significabilidade ao conjunto destas relações de significação. Essa significabilidade é o que forma a estrutura do mundo, daquilo que o Dasein já é desde sempre. (...) Constituição existencial do Dasein e do seu ser-no-mundo, a significabilidade revela a forma, a condição ôntica para a descoberta de uma finalidade total (HEIDEGGER, 1977, p. 116-117, tradução nossa) ${ }^{10}$.

A categoria de Ser-no-mundo parece ser escolhida justamente por melhor representar os propósitos da "virada filosófica". O sentido mesmo do filosofar; sua pertinência e seu pertencimento expressos num único sintagma. Como se todo o caminho percorrido, por exemplo, na Fenomenologia da vida religiosa, pudesse ser condensado numa única expressão. A ideia de mundo em Ser e Tempo é o aprofundamento das intenções expressas nos primeiros escritos.

É preciso notar, todavia, que este uso da palavra mundo, o qual, como já se assinalou exaustivamente, adquire um sentido bastante específico, não é necessariamente o único em Ser e Tempo. Além dele - e também do uso de mundo com aspas, que designa o mundo tal qual compreendido pelo senso comum - a análise existencial da angústia, ainda que de modo muito tímido, acena para uma relação entre mundo e todo. Certamente, não o todo como a reunião de todas as coisas, a soma de todas elas, mas o

${ }^{10}$ No original: "Das Bezugsganze dieses Bedeutens nemen wir die Bedeutsamkeit. Sie ist das, was die Struktur der Welt, dessen, worin Dasein als solches jê schon ist ausmacht. (...) Die erschlossene Bedeutsamkeit ist als existenziale Verfassung des Daseins, seines In-de-Welt-seins, die ontische Bedingung der Möglichkeit der Entdeckbarkeit einer Bewandtnisganzheit." 
todo como relação entre o Dasein e a totalidade do entes. Parece ser esta a compreensão do mundo a exsurgir de uma angústia que já não é a angústia disto, ou daquilo, mas angústia em relação ao todo.

A angústia faz afundar o ser-disponível que ocupa o mundo circundante e, em geral, todo ser intramundando. $\mathrm{O}$ mundo mais nada pode oferecer, como também não pode nada oferecer a coexistência de outrem. A angústia retira do Dasein toda a possibilidade de se compreender, como ele o faz em sua perda, a partir do mundo e da explicação estabelecida publicamente (HEIDEGGER, 1977, p. 249, tradução nossa) ${ }^{11}$.

É, afinal, o todo que ora entra em questão.

A questão do mundo como a questão do todo.

\section{EM DIREÇÃo À PERGUNTA SOBRE O MUNDO}

O ensaio Sobre a essência do fundamento é interessante para se interrogar sobre a ideia de mundo em Heidegger. E o é porque, mais claramente do que em qualquer outro momento de sua obra, Heidegger dedica-se a uma análise histórico-teórica do termo em ao menos três de suas ocorrências: $\kappa o ́ \sigma \mu o \varsigma, ~ m u n d u s$ e Welt. O que se vê ali em curso é uma desconstrução (Destruktion) "das principais significações que se impõem na história do conceito de mundo" (HEIDEGGER, 1991, p. 97).

A hipótese deste artigo é a de que, ao longo das linhas deste texto - não sem alguma divergência com o que o próprio Heidegger pensou do plano geral de sua obra já está em jogo a composição da pergunta sobre o mundo. E o primeiro passo para isso é também um passo; um movimento; um trânsito. Um direcionamento.

"Nós designamos aquilo em direção do qual (horizonte) o ser-aí como tal transcende, o mundo, e determinamos agora a transcendência como ser-no-mundo. Mundo constitui a estrutura unitária da transcendência; enquanto dela faz parte, o conceito de mundo é um conceito transcendental" (HEIDEGGER, 1991, p. 95).

Sobre a essência do fundamento começa a colocar em jogo um novo conjunto de termos, vocábulos e - por que não - conceitos que passam a caracterizar a atitude de Heidegger diante do filosofar. Se o tema do ensaio é o fundamento, ou aquilo que por ele deve entender uma Filosofia que se volta para a existência, é difícil retirá-lo dos caminhos de uma reflexão sobre a finitude. É este último termo que passa a adquirir centralidade em suas análises; termo ao redor do qual gravita a empresa de aprofundar os temas desenvolvidos até Ser e Tempo. A noção de mundo, neste momento, refere-se por completo à ênfase dada sobre a finitude. De tal sorte que a análise histórica do conceito empreendida - ainda que posteriormente Heidegger dirá que o que foi feito se

${ }^{11}$ No original: Die Angst benimmt so dem Dasein die Möglichkeit, verfallend sich aus der 'Welt' und der öffentlichen Ausgelegtheit zu Verstehen. 
resume simplesmente a uma história da palavra (HEIDEGGER, 1995, p. 176-7) - revela mais do que uma ligação ocasional entre finitude e mundo: Heidegger dirá: "[a] tese: da essência do ser aí como tal faz parte o ser-no-mundo contém o problema da transcendência" (HEIDEGGER, 1991, p. 96).

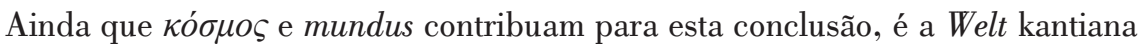
que se sobressai. A noção de finitude que Heidegger ali encontra é decisiva. Se anteriormente, em seus próprios escritos, este último termo se referia ao caráter limitado da existência humana, posto que a morte não era só a projeção de um destino inelutável, mas um determinado modo de experienciar (o mundo), agora com Kant aprofunda-se a idéia de que o conhecimento humano é irremediavelmente finito. A transcendência, em seu caráter altamente ambíguo, pode vir a significar:

sair da experiência do conhecimento finito em geral e representar a possível totalidade de todas as coisas como 'objeto' do intuitus originarius. Nesta transcendência emerge o ideal transcendental, em face do qual mundo representa uma restrição e torna-se expressão do conhecimento finito humano em sua totalidade (HEIDEGGER, 1991, p. 103).

O mundo, por referência à ligadura fundamental entre finitude e transcendência, só pode mesmo ser entendido como a representação de uma totalidade incondicionada. A meio caminho entre a experiência e o ideal transcendental, o mundo é o sinal inarredável da finitude do Dasein.

A idéia de mundo é, de acordo com isto, aquela em que é representada a priori a totalidade absoluta dos objetos acessíveis no conhecimento finito. Mundo designa, por conseguinte, tanto 'conjunto de todos os fenômenos' como 'conjunto de todos os objetos da experiência possível'. Denomina todas as idéias transcendentais na medida em que se referem à totalidade absoluta da síntese por fenômenos, 'conceitos de mundo’ (HEIDEGGER, 1991, p. 101).

Somente enquanto tal pode-se dizer do mundo que ele é horizonte: aquilo em direção a quê se transcende. Contudo - e esta ressalva é sem dúvida a mais importante é um horizonte sem espera, um horizonte que já desde sempre está aí na própria estrutura do Dasein. Este último somente pode ser o que é a partir da transcendência, mas isso não implica a possibilidade de se falar de um antes e de um depois; de um sim e de um não. O Dasein já transcendeu desde sempre, não sendo este movimento parte de nenhuma opção ou cálculo.

De fato, a Filosofia se dá também neste espaço: signo maior da finitude, ela própria é finita, falível, imperfeita, incompleta. Sua própria possibilidade advém do fato da finitude, de seu caráter dado de antemão. O próprio Dasein, ser-no-mundo e transcendente, pode conhecer teoricamente- e aqui se incluiria a objetivação, a subjetivação, a cisão sujeito-objeto - somente a partir do seu ser finito. É ele, e somente ele, que se relaciona com o ente compreendendo o ser, isto é, ele é o ente, dentre todos os entes, capaz de compreender a diferença ontológica. A finitude não só afiança esta relação, mas a conforma, amolda-a. 
Ora, por mais que seja possível retraçar os conceitos de finitude e transcendência em escritos anteriores, parece que Sobre a essência do fundamento opera um salto. A ênfase dada e a importância acordada ao caráter finito de um Dasein ele mesmo cada vez mais central, não representam uma questão de nuances. Há algo de extremamente curioso no modo como Heidegger se reapropria desta temática para radicalizá-la em seguida. O Dasein, em sua finitude irredutível, está cada vez mais só, mais sozinho, mais solitário: mais soberano.

\section{O DASEIN SÓ: A SOBERANIA DO WALTEN}

Foi possível notar, nos dois itens anteriores, como a ideia de mundo ocorre em momentos cruciais da obra de Heidegger. Mais do que assinalar uma espécie de cisão, ou separação nítida de etapas de sua produção filosófica, objetivou-se demarcar um possível diálogo a se estabelecer entre os textos. Diálogo esse - é preciso que se diga - que o próprio Heidegger pretende reorganizar, isto é, organizar a seu modo em razão de um certo argumento que emerge em Os conceitos fundamentais da metafísica: mundo, finitude e solidão. A densidade teórica desse texto mereceria por si só algo muito maior que um simples artigo; e tentar apreendê-la aqui não seria mais do que um delírio. É necessário afunilar, portanto, a análise.

Até este momento, empreendeu-se a tentativa de ler os primeiros escritos de Heidegger - representados, arbitrariamente, pela Fenomenologia da vida Religiosa - ao lado de Sobre a essência do fundamento, com o objetivo de recuperar o caminho que possibilita, a um só tempo, o diálogo-retomada que Heidegger faz de sua própria reflexão sobre o mundo; e a emergência de algo tal como a Soberania. Pode-se, sem dúvida, defender a hipótese de que uma análise das ocorrências do vocábulo mundo e seu significado nos escritos supramencionados preparam a questão do mundo (Weltfrage) que surge agora como ponto central. A palavra preparar pretende deixar ver que a Weltfrage é o agudizar de uma série de reflexões que informam o próprio sentido do filosofar para Martin Heidegger. Contudo, ela não vai sem uma radicalização. E esta radicalização - mormente num período de complexificação política tão extremo - deixa marcas indeléveis e irredutíveis em seus textos. São estes traços que alguém como Jacques Derrida, ao longo do seminário La Bête et le Souverain (DERRIDA, 2010), investigará sob a rubrica de uma desconstrução da soberania.

Mas o que há na pergunta do mundo? O que faz dela algo diferente do caminho que então vinha sendo traçado? O que permite dizer-se que nela o pensamento de Heidegger assume uma coloração tão distintiva?

$\mathrm{O}$ primeiro ponto interessante respeita a uma apropriação que o filósofo realiza de sua própria obra. Uma interpretação - estaria um tentado a dizer - autêntica que permite entrever como o autor se reapropria de suas reflexões. Está em jogo um 
gerenciamento, uma organização dos caminhos eleitos, das vias inscritas, das opções teóricas que foram encaminhadas. A partir delas o quê?

Dirá ele:

O primeiro caminho em direção a uma clarificação inicial exige, como em todos os casos similares, que nós prestemos atenção à palavra e busquemos realizar uma história da palavra mundo e o desenvolvimento histórico do conceito que ela contém. Eu tentei este caminho em Sobre a essência do fundamento. (...) Em contraste com este caminho histórico em direção à compreensão do conceito de mundo, tentei em Ser e Tempo fornecer uma caracterização preliminar do fenômeno mundo interpretando o modo como que primeiramente, e principalmente, nós nos relacionamos em nosso mundo cotidiano (HEIDEGGER, 1995. 176-7, tradução nossa) ${ }^{12}$.

Chama a atenção essa retomada de trabalhos que, sem grandes exageros, são contemporâneos ao seminário que dá origem a Conceitos Fundamentais...: Ser e Tempo é de 1927 e Sobre a essência do fundamento de 1929. Causa estranhamento não apenas a mudança de estratégia, mas a releitura das estratégias anteriores como se já fizessem parte de um passado distante.

Em seguida, é preciso notar como Heidegger mobiliza as hipóteses anteriores para compor uma nova. Dirá ele que, apesar da ligeireza com que tratou a história da palavra mundo - que exigiria mesmo um esforço maior de compreensão -, tal empreitada deve necessariamente ser completada por algo que não pode ser por ela expressado. "A história da palavra fornece apenas o exterior. A história interior envolvida pode ser apenas percebida em conexão com a questão fundamental da metafísica e similarmente a uma compreensão esclarecida da questão do mundo"13 (1995, p. 176, tradução nossa). Ao longo de Sobre a essência do fundamento estava em questão uma temática grecocristiana do mundo, na qual este último termo designava a totalidade dos entes não divinos: tratava-se, portanto, do todo, da completude daquilo que fora criado e permanecia diferente do criador. $\mathrm{O}$ que passa a ser um problema para esta compreensão, sobretudo após Kant, é a presença do homem. Ora, se o homem é essencialmente diferente de Deus, é preciso dizer que ele se encontra inserido no conceito de mundo; mas, certamente, não como os demais entes. O homem não é apenas um ente entre os demais, visto que ele não simplesmente se insere no mundo, mas se situa diante dele, em face, vis-à-vis, gegenuber. Este "estar-diante" é um possuir: o homem possui o mundo. O argumento

${ }^{12}$ Na versão em lingual inglesa: "The first path toward an initial clarification entails, as in all such cases, that we pay close attention to the word and pursue the history of the word 'world' and the historical development of the concept it conatains. I have attempted to pursue this path in my essay On the essence of ground. (...) In contrast to this historical path toward an understanding of the concept of world, I attempted in Being and Time to provide a preliminary characterization of the phenomenon of world by interpreting the way in wich we at first and for the most part move about in our everyday world.

${ }^{13}$ Na versão em língua inglesa: "The history of the word provides only the exterior. The inner history involved can only be perceived in connection with the fundamental problem of metaphysics and along the lines of a clarified understanding of the problem of the world". 
é ambivalente: o homem, entendido aqui como Dasein, faz parte da totalidade dos entes na condição especial de ser o único a fazê-lo estando-diante (gegenuber) e, portanto, possuindo-o; por outro lado, o mundo não pode mais ser entendido somente com recurso à ideia de totalidade dos entes, mas se torna aquilo que, em seu todo, contém o Dasein em sua condição específica. Não há que se falar de mundo sem Dasein. "Com efeito, o homem é, em primeiro lugar, parte do mundo e, em segundo lugar, enquanto parte, é a um só tempo mestre e servo do mundo"14 (HEIDEGGER, 1995, p. 177, tradução nossa).

A experiência do mundo, ou o mundo como experiência, é trabalhada agora como movimento, como caminho em direção ao qual se ergue o próprio caminho. Ao se debruçar sobre o verso de Novalis, Heidegger trará à luz toda a dimensão do mundo como questão. Novamente, isso se dará num contexto de interrogação radical da própria filosofia; a tentativa de, num mundo tomado por completo pela preponderância da técnica e das ciências, encontrar um lugar apropriado, único - solitário, soberano - para o filosofar: distingui-lo radicalmente, enfim. "A Filosofia é propriamente uma saudade de casa, uma pulsão de estar em casa em todos os lugares"15 (NOVALIS apud HEIDEGGER, 1995, p. 5, tradução nossa), diz Novalis. Heidegger lerá aí a melhor definição possível da Filosofia porquanto esteja expressa a questão do mundo. "Em todos os lugares" (uberall) é, em si, não apenas a definição do mundo como totalidade, mas o mundo como essa pulsão que dirige, que empurra, que conduz, que força o Dasein em direção ao todo. Uma força, poder-se-ia, dizer, irresistível. Um walten.

O walten que Jacques Derrida está a investigar. Daí porque: “ [é] o mundo. É a totalidade dos entes. Nossa pulsão nostálgica nos impele em direção à totalidade dos entes" (DERRIDA, 2010, p. 151, tradução nossa) ${ }^{16}$. O vocabulário do caminho - Weg, Bewegung - é fundamental para a compreensão da proposta de Heidegger. Derrida a sintetiza assim:

Eis, portanto, o que é o mundo, a saber, o todo enquanto nós somos o caminho a caminho dele; mas a caminho dele à medida que o caminho aí se traça, se marca, se abre, se inscreve. (...) Nostalgicamente. O impulso ou a pulsão é o que, em suma, longe de nos impulsionar em direção a isto ou àquilo, Ítaca ou Inglaterra, nos impulsiona em direção ao todo, em direção ao mundo enquanto inteireza (DERRIDA, 2010, p. 155, tradução nossa) ${ }^{17}$.

${ }^{14}$ Na versão em língua inglesa: "Thus man is, first, a part of the world, and second, as this part he is at once both master and servant of the world."

${ }^{15}$ Na versão em língua inglesa: "Philosophy is really a homesickness, na urge to be at home everywhere".

${ }^{16}$ No original: “C'est le monde. C'est donc la totalité des étants. Notre pulsion nostalgique nous pousse vers la totalité des étants"

17 No original: "Voilà donc ce qu'est le monde, à savoir le tout en tant que nous sommes ce chemin en chemin vers lui, mais vers lui en tant que le chemin s'y trace, s'y fraie, s'y ouvre, s'y inscrit. (...) Nostalgiquement. La poussée ou la pulsion nostalgique est ce qui, en somme, loin de nous pousser vers ceci ou cela, Ithaque ou Angleterre, c'est ce qui nous pousse vers tout, vers le monde en tant que entier". 
É desse modo que Derrida demonstra como a experiência do mundo contribui para que se avance uma profunda concepção de soberania, sem que Heidegger ao menos utilize esta palavra uma única vez. A soberania do Dasein é sua solidão: brincando com a paronímia de être seul e être le seul, Derrida pretende estudar os jogos, os trânsitos semânticos e sintáticos entre solidão e unicidade, entre estar sozinho e ser a exceção. Afinal, o que se encadeia neste ponto é uma relação de complementaridade e, por isso mesmo, de tensão, entre mundo, finitude e solidão.

O mundo, como pulsão que nos impulsiona, determina de imediato o Dasein como ser finito. Ora, o infinito, seria justamente aquele que permanece imóvel ou num movimento sem retenções; o movimento imparável ou o repouso inalterável. De onde se conclui a um só tempo que toda pulsão só pode impulsionar até certo ponto, devendo necessariamente ser interrompida e que todo homem encontra-se contido na dinâmica pulsão-retenção que caracteriza a finitude. Se assim o é, entretanto, a condição de homem é única, é excepcional, é solitária. Heidegger avançará em seguida o axioma de hierarquização que compreende que a pedra é sem-mundo, o animal é pobre-em-mundo e o homem é criador-de-mundo. Uma separação decisiva, portanto, que está em jogo: o homem só.

No segundo volume de La bête et le souverain, Derrida diz que será uma espécie de advogado de Heidegger (2010, p. 142), seguindo-o até onde for possível. O ponto de ruptura, entretanto, é o que aqui interessa. E ele se dá justamente ali onde Heidegger pretende fazer passar uma diferença fundamental entre o Dasein e o animal. O Dasein, em seu caminho em direção ao todo, é aquele que possui acesso ao todo do ente enquanto tal - a chamada als-Struktur -, isto é, tem acesso à diferença ontológica, ao que distingue ser e ente. Do animal, por outro lado, incapaz de enxergar uma tal diferença e cercado, circunscrito em sua Benommenheit, seu embotamento, não se diz que é capaz de morrer (HEIDEGGER, 1995, 267). Morre aquele que entende a diferença ontológica: só o homem pode morrer; o animal pode apenas perecer.

Nesse sentido, o animal é "pobre-em-mundo", visto que por mais que tenha contato com o Ser, por mais próximo que possa chegar da ideia de uma totalidade do ente, ele permanece inapto a prefigurar a diferença ontológica e, consequentemente, a morte. A morte é o que define o homem ou, em outras palavras, a vida do homem é delineada por sua compreensão da morte.

A questão, para Derrida, é que ao contrário do que o próprio Heidegger fora capaz de perceber, tal entendimento não é o ponto de virada de uma absoluta solidão do homem ou sua absoluta unicidade, mas o questionamento mesmo de qualquer possibilidade de absolutização. A vida carrega em si a morte e vice-versa. Parafraseando Derrida, Martin Hägglund dirá que só não pode morrer aquele que já está morto (HÄGGLUND, 2010, p. 48). A morte, com efeito, é a própria possibilidade da vida que nela se inscreve e a carrega consigo desde sempre. Não há oposição entre o vivo e o 
morto, entre o estar vivo e o estar morto: ao menos não no sentido de uma lógica formal, de um princípio da não contradição. Mais do que se pressuporem, as duas se habitam, co-habitam-se.

Ora, se a vida porta a morte, o Eu carrega o Outro. Já sou o outro de mim mesmo antes de qualquer possibilidade de se falar de um Eu. Essas razões, ao final, vão levar Derrida a suspeitar de toda soberania entendida como isolamento, unicidade e excepcionalidade. Apenas um delírio, um golpe de força (coup de force) assegurado por certo walten poderia enfim promovê-la àquilo que ela diz de si mesma; somente uma violência fundamental teria o poder de obrar para garantir o status do soberano como soberano.

Note-se que, ainda que não apele jamais para a palavra soberania, Heidegger a faz seu tema quando atribui ao homem um poder - único e exclusivo - de compreender a diferença ontológica, de falar e de morrer. $\mathrm{O}$ homem pode isso tudo; ele, diferentemente do animal, é capaz, ele pode. Capacidade e poder são as duas chaves semânticas para compreender o complexo dilema em que Heidegger se colocou. E, precisamente aí, funciona a estratégia de Derrida de ler microscopicamente os deslocamentos havidos ao redor do léxico do walten no corpus heideggeriano. Em três tempos.

1) Ao enfrentar a relação do Dasein com o mundo em Os conceitos fundamentais da metafísica, Heidegger proporá um intercâmbio arriscado entre a Möglichkeit (possibilidade) e o Vermögen (poder), baseado numa raiz comum entre os dois termos. O homem, em seu caráter construtor de mundo, é o único capaz de significar, de usar a palavra atribuindo a ela um sentido. Heidegger se interessa,

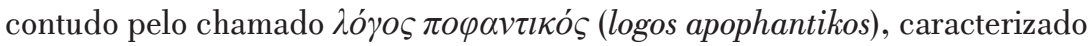
de modo sucinto, como o uso discursivo enunciativo que pode ser dito verdadeiro ou falso (constatativo). Nesses termos, há um pseudesthai original na linguagem, uma espécie de possibilidade do falso inscrita originalmente no logos que é correlata do poder de mentir, de falsear, de iludir, de fingir, de fraudar. Poder esse atribuído exclusivamente ao homem. Esse é o ponto de mediação da análise do walten feita por Derrida, isto é, como um certo poder é o responsável por uma diferenciação hierarquizante entre o homem capaz e o animal incapaz. Diferença essa que se relaciona com o poder de se relacionar com uma diferença.

2) Em Identität und Differenz, texto que data de 1959, Heidegger retorna ao motivo da diferença - notadamente a diferença ontológica que separa ser e ente. Interessa a Derrida notar como isso se dá numa difícil separação entre a mesmidade do mesmo e a alteridade do outro: a sobrevinda do ser e a chegada do ente se pressupõem, estão coimplicadas no predomínio, na prevalência (Walten) de uma certa conciliação entre eles. Dificilmente seria possível 
abranger toda a dimensão desta proposta de Heidegger; cumpre ressaltar somente que o léxico do Walten está ligado à diferença ontológica - a diferença das diferenças que se dá por meio de uma identidade; uma arque-diferença e à conciliação entre a chegada e a sobrevinda, i.e., um conjunto de conceitos ligados pela ideia do sobre-, do Uber correlato da preposição latina super presente em superanus (soberano).

3) Derrida retorna em seguida ao fundamento da investigação, a saber, como a temática da diferença ontológica por uma lado e da posição privilegiada do homem em relação à compreensão dessa diferença, por outro, inscrevem-se conjuntamente numa questão sobre sobre o mundo: Was ist Welt? É normal que assim seja, uma vez que o comum, o em-comum, o estar-junto-de em algum lugar é que perfaz a experiência mais abrangente da ideia de mundo. Homem e animal partilham o mundo - como? -, mas aquele o faz a partir de uma transcendência, da emergência de um certo poder. "As coisas se complicam, entretanto, no momento de interpretar esse poder como soberania" (DERRIDA, 2010, p. 381, tradução nossa). Ainda em Identidade e Diferença, Heidegger afirmará que a constituição onto-teológica da metafísica procede do Walten da diferença ontológica, isto é, o Deus todo-poderoso, Causa sui, que adentra a filosofia num momento específico de sua história, pode ser somente dito ôntico; circunscrito e limitado ao ôntico. Em outras palavras, dir-se-ia que o Deus metafísico é também um esquecimento do ser e do predomínio da diferença. Algo similar ocorre em Introdução à Metafísica ${ }^{18}$. Nesse texto, Heidegger aborda a prevalência, o reinar (walten) da poesia e do espírito em relação à ciência. Uma espécie de superioridade (Ubergelegenheit) de algo que simplesmente não é algo, não é uma coisa, não é um ente. Mais adiante, entretanto, ele irá aprofundar essa análise por meio de uma leitura do Édipo Rei na qual pretende marcar que o violento (Das Gewaltige), o sobreviolento (Ubergewaltige), a superpotência, o sobrepoder, são características essenciais do Walten. Este último termo, que tem sido aqui tratado em toda sua intraductibilidade, é o que fecha a cadeia conceitual ora estudada. $O$ ente no seu todo, em sua totalidade, ou seja, o ser do ser-ente se assemelha ao Walten como se sinônimos fossem. Portam em si a medida de uma violência fundadora, de um poder originário não violento e não poderoso, visto que, a rigor, não é nada, não é como coisa. O léxico do super, da superioridade distintiva e solitária, é o tonalidade afetiva de todo o discurso. Derrida finaliza dizendo:

${ }^{18}$ Há uma série de questão neste livro que podem ser abordadas apenas superficialmente aqui. A leitura feita por Heidegger de Édipo Rei contém, entretanto, diversas pistas importantes para se pensar a soberania, o soberano e o Estado. Ver HEIDEGGER (1967). 
Mas o que assim se esquece é que o homem é tomado, atravessado, durchwalten pela Gewalt deste walten e, porque se esquece e se atribui a este homem, como a um sujeito, a iniciativa ou a invenção da linguagem, da compreensão, etc., é por essa razão que o homem torna-se paradoxalmente estranho a sua própria essência. Por que ele acredita ser o autor, o mestre e possuidor e o inventor destes poderes, ele ignora que é, em primeiro lugar, atravessado, tomado (...) (DERRIDA, 2010, p. 394, tradução nossa) ${ }^{19}$.

\section{E mais adiante:}

Porque tudo isto diz respeito à historialidade reservada ao Dasein e ao ser, negada ao animal e às outras formas de vida. Há historicidade do homem (e não do animal) somente ali onde a Gewalt deste Walten irrompe para fazer aparecer o ente enquanto tal, no meio do qual o homem é atravessado de violência (DERRIDA, 2010, p. 395, tradução nossa) ${ }^{20}$.

Em resumo, seria possível dizer que o Walten corresponde a esta violência não violenta relativa à superioridade originária de uma distinção fundamental - ontológica, neste sentido. Violência, superioridade, distinção, características normalmente atribuídas à soberania, mas que aqui se referem ao Walten: uma arquessoberania para além da ontoteologia de uma metafísica circuscrita ao ôntico.

Uma última vez, Derrida:

Agora, tendo feito esta recapitulação bastante sumária, se insisto tanto na palavra Walten, e em todas as ocorrências impressionantes deste verbo, às vezes nominalizado, ao longo do corpus de Heidegger após Sein und Zeit, é porque aparecendo, como nós vimos, em nosso Seminário de 1929-30, elas parecem conclamar uma soberania de última instância, a um sobre-poder que decide sobre tudo em última instância e, em particular, quanto ao enquanto tal, quanto à diferença entre ser e ente, à Austrag, como nós falávamos na semana passada, mas que conclama uma soberania tão soberana que ela excede as figuras ou as determinações teológicas e políticas - e sobretudo onto-teológicas da soberania. O walten seria tão soberano, ultra-soberano em suma, que ele estaria ainda liberto de todas as dimensões antropológicas, teológicas e políticas, logo, ônticas e onto-teológicas da soberania (DERRIDA, 2010, p. 382, tradução nossa) ${ }^{21}$.

19 No original: "Mais ce qu'on oublie alors, c'est que l'homme est saisi, transi, durchwalten par la Gewalt de ce Walten, et c'est parce qu'on oublie et qu'on lui attribue, à cet homme, comme à un sujet, l'initiative ou l'invention du langage, de la compréhension, etc., c'est pour cela que l'homme est paradoxalement devenu étrange à sa propre essence. Parce qu'il croit être l'auteur, le maître et possesseur, et l'inventeur de ces pouvoirs, il ignore qu'il en est d'abord transi, saisi (...)".

${ }^{20}$ No original: "Car tout ceci concerne l'historialité réservé au Dasein et à l'être, deniée à l'animal et aux autre formes de vie. Il n'y a d'historicité de l'homme (et non de l'animal) que là où la Gewalt de ce Walten fait irruption pour faire apparaître l'étant comme tel au milieu duquel l'homme est transi de violence".

${ }^{21}$ No original: "Maintenant, ce rappel plus que sommaire étant fait, si j’insiste tant sur le mot 'Walten', et sur toutes les occurrences saisissantes de ce verb, parfois nominalisé, tout au long du corpus de Heidegger après Sein und Zeit, c'est que apparaisant, nous l'avons vu, dans notre Séminaire de 1929-30, elles semblent appeler à une souveraineté de dernière instance, à un surpouvoir qui décide de tout en dernière instance, et en particulier quant au en tant que tel, quant à la différence entre l'être et l'étant, à la Austrag dont nous parlions à la semaine passée, mais qui en appelle à une souveraineté si souveraine qu'elle excède les figures ou les déterminations 
O traçado que explica esta ideia Derrida é a um só tempo complexo e bastante simples. Como fora visto, todas as vezes que Heidegger mobiliza o conceito de mundo, ele está também dizendo algo sobre a filosofia; trata-se sempre de uma virada da filosofia, algo que a coloque num patamar diferente daquilo que o senso comum e o senso comum filosófico entendem por conhecimento, sobretudo a partir da imagem da ciência. $\mathrm{O}$ mundo define também, em seu pensamento, o vetor primordial para a compreensão da relação entre ser e ente por meio do Dasein - o ser humano destituído da carga antropoteo-lógica que sedimentou nossa pré-compreensão. O ser humano é aquele que possui o mundo, é seu senhor e seu escravo e caminha em direção a ele por uma pulsão inelutável. Esta mesma pulsão, baseada em sua capacidade de se relacionar com o ente enquanto tal, de compreender a diferença ontológica, é o que o faz não ser apenas um ente dentre os demais no mundo: é o que o separa soberanamente do animal. Entretanto, e isso não poderia escapar jamais de um texto com viés desconstrutivo, a característica mais essencial do Dasein, a Gewalt do walten, não o pertence; atravessa-o. É o verbo walten, com toda sua poesia, com toda sua intraductibilidade, que comanda o léxico da proposta heideggeriana: walten como acontecimento, origem, poder, força, potência, fonte, movimento, processo. Trata-se de uma predominância do mundo, de uma força acima de todas as outras.

\section{CONCLUSÃO}

O intento deste artigo não foi outro senão o de pensar ferramentas teóricas para se abordar a Soberania como problema fundamental da contemporaneidade. Por não julgar plenamente hábil a fazê-lo o instrumental teórico habitual utilizado na Filosofia Política e na própria Filosofia do Direito é que se arriscou um percurso inabitual. Compreender a soberania a partir de um autor que, em princípio, não diz nada sobre ela. Ao menos, não expressamente; ao menos não deliberadamente, ainda que o valor de objetividade desta última afirmação possa ser questionado infinitamente. Tentou-se aqui, ampliando o escopo de um convite feito por Jacques Derrida naquele que fora seu último seminário na École des Hautes Études en Sciences Sociales, estudar a ascensão da questão do mundo, Weltfrage, ao longo de um intenso processo de encadeamentos conceituais que conformam a história do termo mundo no interior do pensamento de Martin Heidegger. Justamente ele que se recusara categoricamente a falar sobre Ética e Política, uma vez que essas disciplinas nada tinham a dizer sobre aquilo que realmente lhe importava, a saber, o próprio Ser.

théologiques et politiques - et surtout onto-théologiques de la souveraineté. Le walten serait si souverain, ultrasouverain en somme, qu'il serait encore denué de toutes les dimensions anthropologiques, théologiques et politiques, donc ontiques et onto-théologiques de la souveraineté". 
Fora necessário recapitular - não sem uma dose de arbitrariedade em certos recortes, em certas escolhas - o desenvolvimento da ideia de mundo em etapas diferentes da obra de Heidegger. Viu-se, assim, como se deu uma transição sem suprassunção, sem Aufhebung, de uma ideia de mundo como arqueconexão e matriz de significabilidade, para uma noção mais caracterizada pelo todo do ente enquanto caminho em direção ao qual caminha o homem, o Dasein. Essa passagem fora mesmo possível apenas com recurso a um conjunto de poderes, pertencentes exclusivamente ao humano, que o separam em definitivo da animalidade: poder-compreender a diferença entre ser e ente (diferença ontológica); poder-linguagem; poder-morrer. O homem é, nesse sentido, atravessado, constituído e constituinte de um walten, palavra de impossível tradução que organiza a força-violência arquessoberana do mundo.

Seguindo de perto as impressões de Jacques Derrida, pode-se compreender que Heidegger enuncia um princípio de soberania absolutamente inovador - que, em verdade, o torna ainda mais problemático. O walten a que se refere é uma soberania para além de toda e qualquer soberania - sobretudo em sua matriz teológico-política. É de se pensar como estão abertas, assim, linhas de investigação extremamente sugestivas. Aquela que parece ser a mais óbvia, ainda que não seja a única, é a de pensar os efeitos de uma arquessoberania em relação ao locus principal da discussão sobre soberania no século XX, ou seja, a frase de abertura da Teologia Política de Carl Schmitt: "Soberano é aquele que decide sobre o Estado de Exceção" (SCHMITT, 2004, p. 13, tradução nossa) ${ }^{22}$. Contra uma teoria da secularização que pretenderia ver na Teoria do Estado nada mais do que conceitos teológicos secularizados, o que poderia significar uma soberania que se desprendesse de uma ontoteologia, que de livrasse da imagem de um Deus-ente, de um Deus como ente-supremo. Qual soberania? Parodiando Derrida, perguntar-se-ia: soberania - qual gênero? Noutras palavras, uma concepção de soberania sem soberania que apelaria, em verdade, a uma arquessoberania, não é já em si, em seu próprio movimento sobre si, em sua própria lógica que desafia o princípio da não contradição, a desconstrução da soberania? Não seria já a desconstrução como desconstrução de toda soberania; como lembrança do caminho de desconstrução que desconstrói toda e qualquer pretensão à soberania da solidão, da unicidade, da insularidade, da exceção?

As consequências disso para a Teoria da Constituição e para a Teoria do Direito Internacional podem ser imensas. No ponto que aqui se encerra, ao fim deste artigo, contudo, não há nenhuma garantia. Não há, sob nenhum modo, garantia de que a soberania do walten possa ser pensada como passo em direção a uma superação do modelo que é ainda hegemônico: aquele da Soberania do Estado-Nação, força maior exercida sobre homens sedentários dentro de um território (JELLINEK, 1911, p. 282 et

\footnotetext{
${ }^{22}$ No original: "Souverän ist wer uber den Ausnahmezustand entsheidet".
} 
seq.) e força imunizadora contra toda normatividade que lhe seja exterior, o que comanda um relacionamento com outros soberanos fundado num Direito Inter-Nacional (DELMASMARTY, 2007, 73 et. seq). Ora, como fora visto, a soberania para além da soberania é, antes de mais nada, um risco enorme. Talvez, entretanto, seja exatamente na rachadura deste risco que o impossível possa ocorrer, a vinda do inesperado, a possibilidade do im-possível.

\section{REFERÊNCIAS}

DELMAS-MARTY, Mireille. Les forces imaginantes du droit (iii): la refondations des pouvoirs. Paris: Seuil, 2007.

DELMAS-MARTY, Mireille. Les forces imaginantes du droit (i): le relatif et l'universel. Paris. Seuil, 2004.

DERRIDA, Jacques. Séminaire La bête et le soouverain: volume II (2002-2003). Paris: Galilée, 2010.

DILTHEY, Wilhelm. Poetry and experience. Princeton: Princeton University Press, 1985

DREYFUS, Hubert. Agir, intentionnalité et être-au-monde. In:. Le rôle de l'action dans la constitution du monde chez Husserl et Heidegger. In: Philosophiques, vol. 20, n 2, 1993, p. 285-302.

ELSTER, Jon. Ulysses unbound: studies in rationality, precommitment and constraints. Cambridge: Cambridge University Press, 2000.

FØLLESDAL, Dagfinn. Le rôle de l'action dans la constitution du monde chez Husserl et Heidegger. In: Philosophiques, vol. 20, n ${ }^{\circ}$, 1993, p. 267-284.

HABERMAS, Jurgen. Between facts and norms: contributions to a discourse theory of law and democracy. Trad. William Rehg. Cambridge: The MIT Press, 1996.

HÄGGLUND, Martin. Radical atheism: Derrida and the time of life. Stanford: Stanford University Press, 2008.

HEIDEGGER, Martin. Fenomenologia da Vida Religiosa. Trad. Enio Paulo Giachini et al.

Petrópolis: Ed. Vozes, 2010.

HEIDEGGER, Martin. Introduction à la métaphysique. Paris: Éditions Gallimar, 1976.

HEIDEGGER, Martin. Sein und Zeit. Tubingen: Max Niemayer, 1976.

HEIDEGGER, Martin. Sobre a essência do fundamento. In: Martin Heidegger: conferência e escritos filosóficos (Os pensadores). Trad. Ernildo Stein. São Paulo: Nova Cultural, 1991.

HEIDEGGER, Martin. The fundamental concepts of metaphysics: world, finitude, solitude. Trad. William McNeill e Nicholas Walker. Indianapolis: Indiana University Press, 1995.

HELLER, Hermann. La soberania. México, DF: Universidad Nacional Autónoma de México, 1965.

HUSSERL, Edmund. Cartesian meditations: na introduction to phenomenolgy. Trad. Dorion Cairns. A Haia: Martinus Nijhoff, 1982.

HUSSERL, Edmund. Ideas pertaining to a pure phenomenology and to a phenomenological philophy. Trad. F Kersten. A Haia: Martinus Nijhoff, 1983.

JACOBSON, Arthur; SCHLINK, Bernhard. Weimar: a jurisprudence of crisis. Berkeley: University of California Press, 2000. 
JELLINEK, Georg. L'État moderne et son droit. Paris: V Giard \& E Briere, 1911.

MARRAMAO, Giacomo. Dopo il Leviatano: individuo e comunità. Torino: Bollati Boringhieri, 2000.

MARRAMAO, Giacomo. Kairós: apologia del tempo debito. Roma: Laterza, 2005.

SCHMITT, Carl. Politische Theologie: vier Kapitel zur Lehre von der Souveränität. Berlin: Dunker \& Humblot, 2004.

SCHMITT, Carl. Teoria de la constitucion. Madrid: Alianza, 1982.

STEIN, Ernildo. Mundo vivido: das vicissitudes e dos usos de um conceito da fenomenologia. Porto Alegra: EDPUCRS, 2004.

WITTGENSTEIN, Ludwig. Tractatus Logico-philosophicus. Trad. Gilles Gaston Granger. Paris:

Gallimard, 1993. 